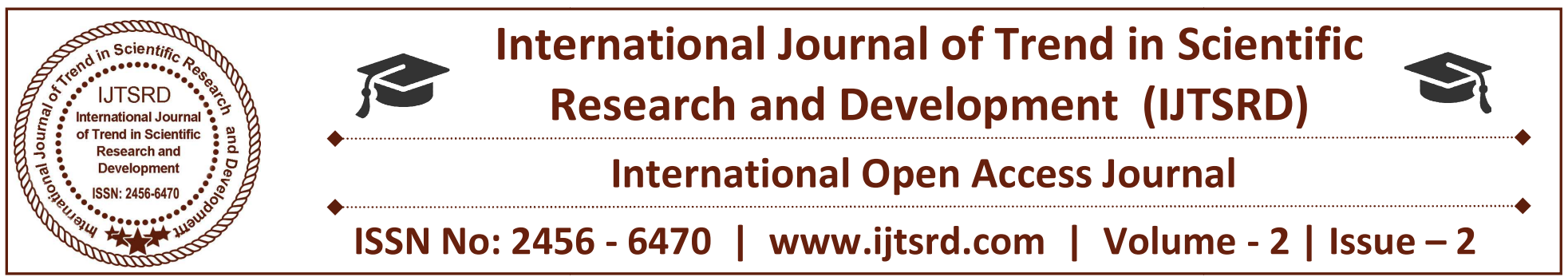

\title{
Geochemicals Heavy Metal Pollution of River Ganga - Causes And Impacts
}

\author{
Hasnahara Khatun \\ Research Scholar, P.G Department of Environmental \\ Science, Magadh University, \\ Bodh Gaya, Bihar, India
}

\author{
Dr. Arshad Jamal \\ Research Guide, Soghra College, \\ Biharsharif, Nalanda, Bihar, India
}

\section{ABSTRACT}

River Ganga is considered sacred by people of India for providing life sustenance to environment and ecology. Anthropogenic activities have generated important transformations in aquatic environments during the last few decades. Human civilization has put serious questions to the safe use of river water for drinking and other purposes. The river Ganga water pollution due to heavy metals is one of the major concerns in most of the metropolitan cities of developing countries. Heavy metal concentration in sediments of Ganga River was studied significant difference between sites situated upstream and downstream of Varanasi urban core. Metal concentration increased consistently along the study gradient, indicating the influence of urban sources. These toxic heavy metals entering the environment may lead to bioaccumulation and bio-magnifications. These heavy metals are not readily degradable in nature and accumulate in the animal as well as human bodies to a very high toxic amount leading to undesirable effects beyond a certain limit. Heavy metals in the river, environment represents an abiding threat to human health. Exposure to heavy metals has been linked to developmental retardation, kidney damage, various cancers, and even death in instances of very high exposure. The following review article presents the findings of the work carried out by the various researchers in the past on the heavy metal pollution of river Ganga.

Keywords: Ganga, health, heavy metals, urban, sediment

\section{Introduction}

The entry of contaminants into the environment due to human and natural activities is one of the most important issues facing today's communities. Due to the industrial and economic growth and the production of a variety of compounds and chemicals followed by increased consumption man makes some unwanted pollutants, many of which cause serious problems and risks for the environment and for man himself. The most important natural resources of environmental pollution are soil and rock weathering and natural events such as earthquakes and floods.

The term "heavy metal" is not altogether clearly defined, but in the case of water pollution, these are metals such as arsenic, cadmium, iron, cobalt, chromium, copper, manganese, mercury, molybdenum, nickel, lead, selenium, vanadium and zinc. While heavy metals do tend to have a high atomic mass, and so are heavy in that sense, toxicity seems to be a further defining factor.

Heavy metals occur in the earth's geological structures, and can therefore enter water resources through natural processes. For example, heavy rains or flowing water can leach heavy metals out of geological formations. Such processes are exacerbated when this geology is disturbed by economic activities such as mining. These processes expose the mined-out area to water and air, and can lead to consequences such as acid mine drainage (AMD). The low $\mathrm{pH}$ conditions associated with AMD mobilise heavy 
metals, including radionuclides where these are present. Mineral processing operations can also generate significant heavy metal pollution, both from direct extraction processes (which typically entail size reduction - greatly increasing the surface area for mass transfer - and generate effluents) as well as through leaching from ore and tailings stockpiles.

mining activity poses significant risks for heavy metal pollution, this sector is not the only culprit in the industrial sector. Many industrial processes can generate heavy metal pollution, and in a large number of ways. Clearly, some industries will be more likely to pollute than others. Hence the electroplating industry, which can produce large volumes of metalrich effluents, will naturally be a more likely polluter than the food processing industry, for example. This is not to say that players in this industry will necessarily pollute, and it is in fact in the electroplating industry's best economic interests to minimise metal discharges, since these are inversely proportional to resource efficiency. Reducing losses by minimising drag-out from plating baths leads to reduced metal discharges, for example. The lead-acid battery manufacturing industry is another example of an industry which can generate metal-rich effluents as well as airborne lead pollution which can subsequently be deposited in surface water resources (and of course on land). So clearly, where an industry uses heavy metals as key input materials, pollution risks increase.

An example of a large non-point source of heavy metal pollution is coal-fired power generation, which can contaminate water resources through aerial deposition of mercury emitted from boiler flues. Technologies such as wet scrubbing are available to remove much of this mercury, but of course the effluents produced have to be safely handled to prevent subsequent pollution. Some of these processes have the primary goal of removing sulphur dioxide, with heavy metal removal a welcome by-product of the scrubbing process. The industry also generates large amounts of ash which itself contains heavy metals, including uranium.

\section{Study Area}

My study sites the Ganga River covering upstream to downstream urban core of Varanasi $\left(25^{\circ} 18^{\prime} \mathrm{N}\right.$ lat. and $83^{\circ} 1^{\prime} \mathrm{E}$ long.). Sites were selected on the basis of catchment characteristics and sources of input. My Sites are relatively natural, and the rest of the sites are invariably human influenced. The river along the city receives sewage from the Nagwa drain located upstream to AssiGhat, Shivala drain located between AssiGhat and DashashwamedhGhat, and Khirki drain situated downstream Rajghat.

\section{Materials and Methods}

\section{Sample Collection in Ganga}

After determining the location of the sampling points before and after the entry of the sewage, 36 samples (18 water samples and 18 sediment samples) were collected by grab method for 6-year period; 3 samples of water and 3 samples of sediment were collected in every month and 3 liters of water was collected in each of sampling from below the water surface and $30 \mathrm{~g}$ of sediment samples from a depth of $20 \mathrm{~cm}$ under the ganga bed river were collected. Samples of water acidified with nitric acid $(\mathrm{PH}=2)$ along with other samples were transferred to the laboratory.

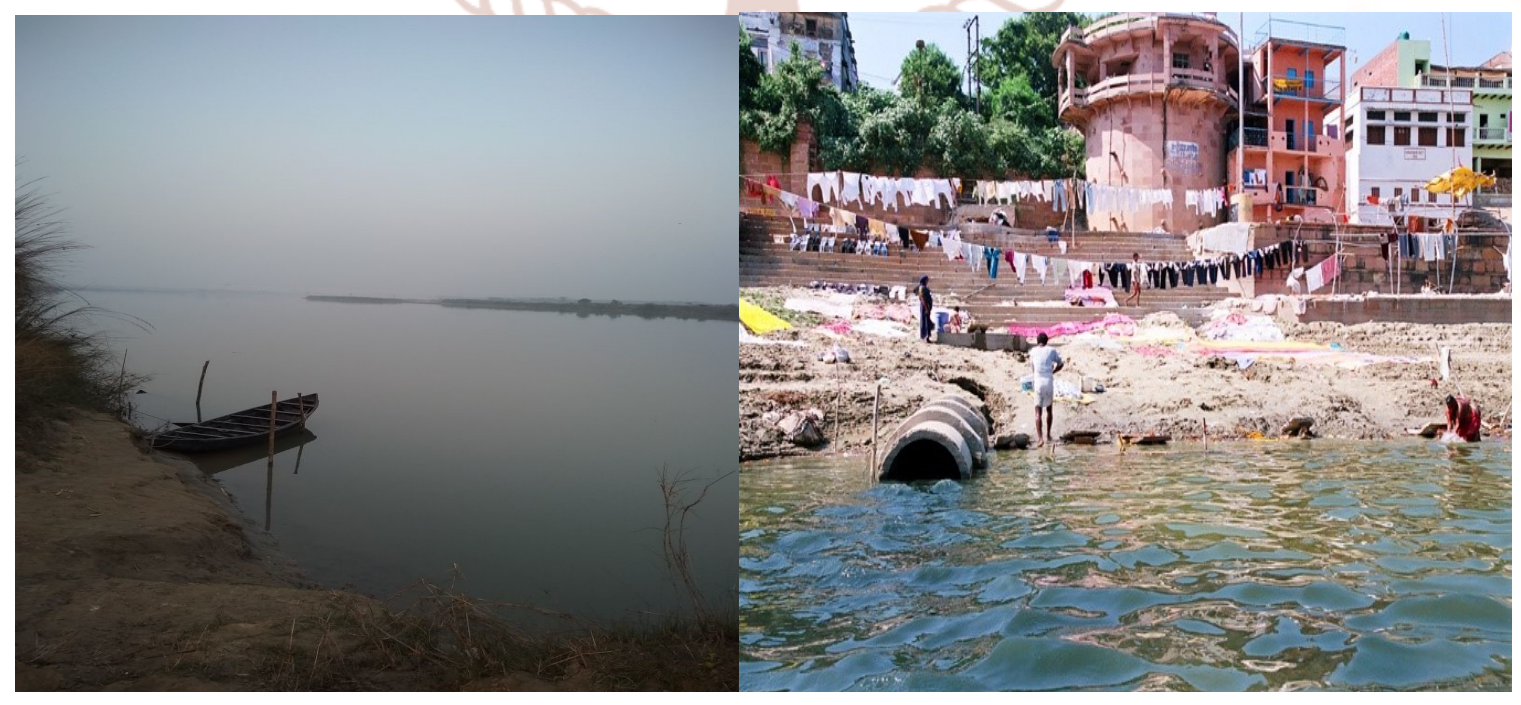




\section{GANGA SAMPLING SITES}

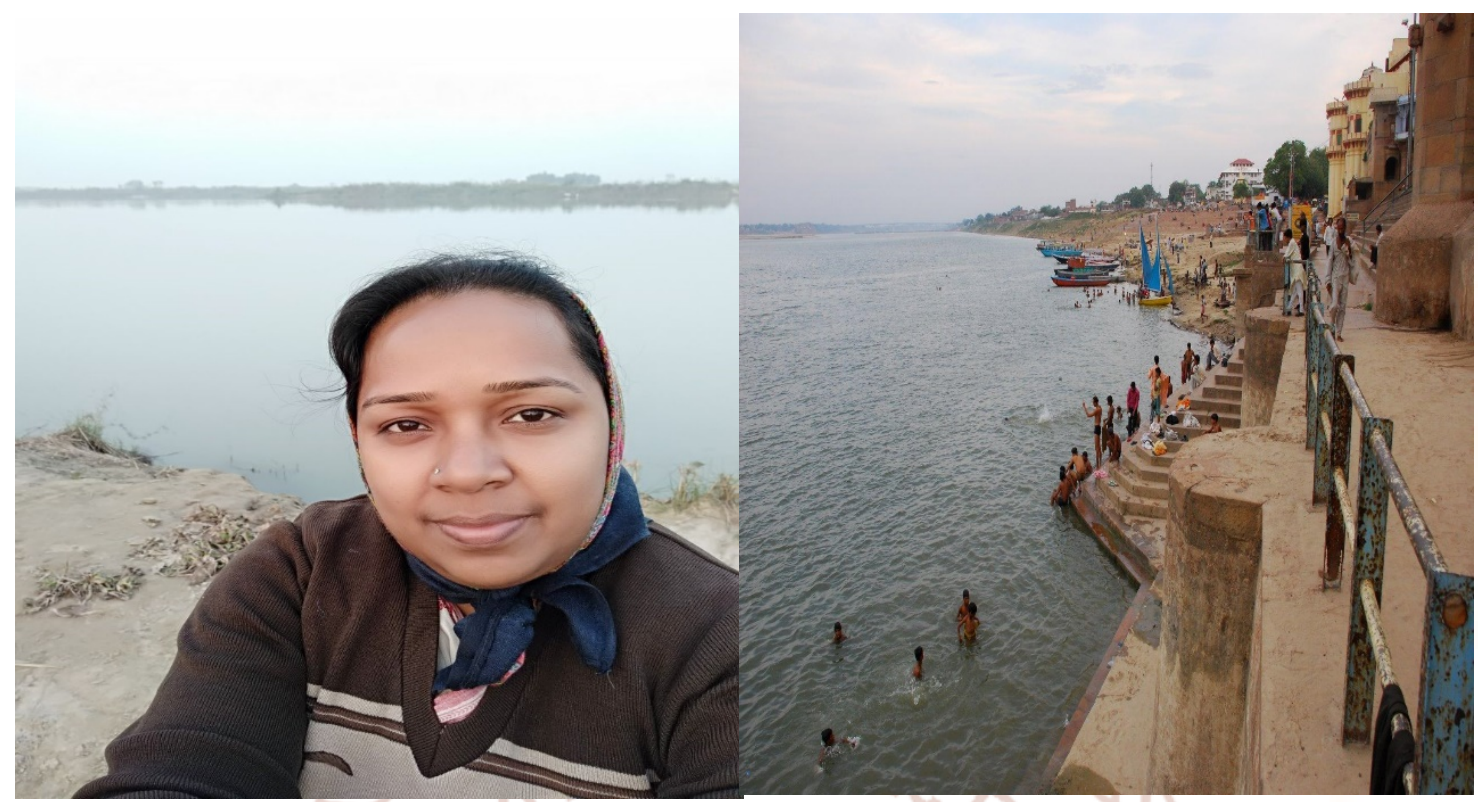

\section{RESEARCH SCHOLAR AND SAMPLING SITE OF GANGA}

\section{Sediment Samples Preparation}

$30 \mathrm{~g}$ of sediment samples was dried at $103^{\circ} \mathrm{C} .1 \mathrm{gram}$ of each sample was weighed carefully and $5 \mathrm{~mL}$ of concentrated nitric acid was added to each sample. The sample, then, was heated up to $83^{\circ} \mathrm{C}$ until near dryness. The addition of acid and the process of heating were repeated 3 more times. An amount of water was added to the residual material. The suspension was filtered (Whatman filter Merck, $0.45 \mu \mathrm{m})$ and the filtrate was diluted by deionized water to a final volume of $50 \mathrm{~mL}$.

\section{Water Samples Preparation}

3 liters of each collected water sample was first concentrated on a sandy oven at $83^{\circ} \mathrm{C}$ until the volume reached $50 \mathrm{~mL}$. Then $4 \mathrm{~mL}$ concentrated sulfuric acid (Merck, 98\%) was added to each sample and Digested by digesdahl apparatus for 2 minutes. The $10 \mathrm{~mL}$ hydrogen peroxide (Merck, 30\%) was then added and heated until oxidation was completed. After cooling, each sample filtered by filter Whatman filter Merck, $0.45 \mu \mathrm{m}$. The filtrate was diluted by deionized water to a final volume of $50 \mathrm{~mL}$.

\section{Samples Analysis}

The prepared samples were analyzed by a Graphite furnace atomic absorption spectrometry to determine the metals.
Statistical Analysis of Variance, t-Test, and Least Significant Differences Test That Means "LSD"

It was conducted to determine the difference of metal ion concentrations among the water and sediment in upstream and downstream of River ganga in different seasons. A value $\leq 0.06$ was considered significant. The correlation analysis was also carried out to determine the relationship between the concentration of metal ions in water and sediment.

\section{Research Result}

The results of the analysis of water and sediment samples in upstream and downstream of the river revealed that the mean concentration of $\mathrm{Cd}, \mathrm{Cr}, \mathrm{Cu}$, $\mathrm{Fe} \mathrm{Mn}, \mathrm{Pb}$, and $\mathrm{Zn}$ in the downstream water was higher than that in the upstream water in different seasons. the effect of the entry of sewage untreated municipal sewage, runoff, abattoir wastewater, and leachate of solid wastes around the river ganga the concentration of $\mathrm{Cd}, \mathrm{Cr}, \mathrm{Mn}$, and $\mathrm{Ni}$ in this ganga river is higher than the stated standard level for it, and that its water is harmful to the human health .

These results show the effect of dry seasons and water evaporation on concentration increase of heavy metals in water. their research that dry seasons affect the accumulation of heavy metals in water and its reared fish. the seasonal distribution of $\mathrm{Cd}, \mathrm{Cr}, \mathrm{Cu}, \mathrm{Ni}$, and $\mathrm{Pb}$ varies seasonally. heavy metals in the River ganga water with the standard value in drinking water and those in the water used for agriculture for aquatic life 
and surface water standards suggests that the mean concentration of $\mathrm{Cu}$ within the standard range for drinking water and the mean concentrations of $\mathrm{Mn}$ and $\mathrm{Cd}$ within the standard range of agricultural water.the mean concentrations of $\mathrm{Zn}$ within the standard range for all three kinds of water. In River gangawater is not suitable for drinking and aquatic life. Mean concentrations of $\mathrm{Cd}, \mathrm{Cr}, \mathrm{Mn}$, and $\mathrm{Pb}$ were higher than surface water standards.

The Riverganga downstream have increased in comparison with those in its upstream. The maximum and minimum levels of concentration are related to $\mathrm{Mn}$ in downstream and $\mathrm{Cd}$ in upstream areas, respectively. Regarding the rise in the concentrations of these metals in downstream water, the higher concentrations in downstream sediment are very reasonable. In fact; increased heavy metals concentration in water in downstream lead to increasing of their concentration in sediment in downstream. The sediments of the river upstream, where the sewage enters River Ganga, changes similarly in four seasons. The average concentration of metals in sediments in Autumn and Winter is lower than that in Summer. These amounts rise again when Summer starts. The amounts of heavy metals in sediment varied seasonally as follows:

Summer season $>$ Winterseason $>$ Spring season

The cause of these changes was high rain in rainy season and Winterseason which gives rise to flow of the water in the river ganga. Due to the turbulence created by increase of flow, some sediments and heavy metals inside them are displaced and carried away from the river bed. As Summer starts, the rise in temperature and evaporation and the end of the rain period cause the rise in heavy metals concentration in water and finally in sediments because metal ions transfer from water to sediment. The seasonal variation of distribution of $\mathrm{Cd}, \mathrm{Cr}, \mathrm{Cu}, \mathrm{Fe}, \mathrm{Mn}, \mathrm{Ni}$, $\mathrm{Pb}$, and $\mathrm{Zn}$ in the sediment.these metals with the standards for fresh water sediments indicates that, except $\mathrm{Zn}$, the mean concentrations of $\mathrm{Cd}, \mathrm{Cr}, \mathrm{Cu}, \mathrm{Ni}$, and $\mathrm{Pb}$ were higher than the standards for fresh water sediments while only the mean concentrations of $\mathrm{Cd}$ in marine sediments were higher than the standards.

\section{Conclusion}

Summarize the current situation of heavy metal pollution in the river Ganga. Several studies of heavy metal pollution. The levels of various heavy metals in the river Ganga water and sediment are far above the acceptable concentrations. The metals enter the environment through aquatic life systems and plants and animals surrounding the river. The hazard of bioaccumulation and bio-magnification of the heavy metals make them a big risk to human health.

\section{Reference}

1. Copaja SV, Molina X, Tessada R (2014) Determination of heavy metals in Choapa River sediments using BCR sequential extraction procedure. J ChilChemSoc 59(1):2353-2358

2. Dhanakumar S, Mani S, Murthy RC, Veeramani M, Mohanraj R (2011) Heavy metals and their fractionation profile in surface sediments of upper reaches in the Cauvery. Int J Geol Earth Environ Sci 1:38-47

3. District Industrial Profile (DIP) (2013) Varanasi. Ministry of micro, small and medium interprises, Government of India

4. Esen E, Kucuksezgin F, Uluturhan E (2010) Assessment of trace metal pollution in surface sediments of Nemrut Bay, Aegean Sea. Environ Monit Assess 160:257-266

5. Ghrefat HA, Abu-Rukah Y, Rosen MA (2011) Application of geo accumulation index and enrichment factor for assessing metal contamination in sediments of Kafrain Dam, Jordan. Environ Monit Assess 178:95-109

6. Prabhashkumar, p.gdept of environmental science,M.U IJTSRD9421 ISSN2456-6470

7. Goorzadi M, Vahabzadeh GH, Ghanbarpour MR, Karbassi AR (2009) Assessment of heavy metal pollution in Tilehbon River sediments, Iran. J ApplSci 9:1190-1193

8. Jayaprakash M, Jonathan MP, Srinivasalu S, Muthuraj S, Ram-Mohan V, Rajeshwara-Rao N (2008) Acid-leachable trace metals in sediments from an industrialized region (Ennore Creek) of Chennai City, SE coast of India: an approach towards regular monitoring. Estuar Coast Shelf Sci 76:692-703

9. Kumar RN, Solanki R, Kumar JN (2013) Seasonal variation in heavy metal contamination in water and sediments of river Sabarmati and Kharicut canal at Ahmedabad, Gujrat. Environ Monit Assess 185:359-368 